\title{
Association of persistent wild-type measles virus RNA with long-term humoral immunity in rhesus macaques
}

\author{
Ashley N. Nelson, ${ }^{1}$ Wen-Hsuan W. Lin, ${ }^{1}$ Rupak Shivakoti, ${ }^{1}$ Nicole E. Putnam, ${ }^{1}$ Lisa Mangus, ${ }^{2}$ \\ Robert J. Adams, ${ }^{2}$ Debra Hauer, ${ }^{1}$ Victoria K. Baxter, ${ }^{1}$ and Diane E. Griffin' \\ ${ }^{1}$ W. Harry Feinstone Department of Molecular Microbiology and Immunology, Johns Hopkins Bloomberg School of Public \\ Health, Baltimore, Maryland, USA. ${ }^{2}$ Department of Molecular and Comparative Pathobiology, Johns Hopkins University \\ School of Medicine, Baltimore, Maryland, USA.
}

\begin{abstract}
Recovery from measles results in life-long protective immunity. To understand induction of long-term immunity, rhesus macaques were studied for 6 months after infection with wild-type measles virus (MeV). Infection caused viremia and rash, with clearance of infectious virus by day 14. MeV RNA persisted in PBMCs for 30-90 days and in lymphoid tissue for 6 months most often in $B$ cells but was rarely detected in BM. Antibody with neutralizing activity and binding specificity for $\mathrm{MeV}$ nucleocapsid $(\mathrm{N})$, hemagglutinin $(\mathrm{H})$, and fusion proteins appeared with the rash and avidity matured over 3-4 months. Lymph nodes had increasing numbers of MeV-specific antibodysecreting cells (ASCs) and germinal centers with late hyalinization. ASCs appeared in circulation with the rash and continued to appear along with peripheral $\mathrm{T}$ follicular helper cells for the study duration. ASCs in lymph nodes and PBMCs produced antibody against both $\mathrm{H}$ and $\mathrm{N}$, with more $\mathrm{H}$-specific ASCs in BM. During days 14-21, 20- to 100-fold more total ASCs than MeV-specific ASCs appeared in circulation, suggesting mobilization of preexisting ASCs. Therefore, persistence of $\mathrm{MeV}$ RNA in lymphoid tissue was accompanied by continued germinal center formation, ASC production, avidity maturation, and accumulation of $\mathrm{H}$-specific ASCs in BM to sustain neutralizing antibody and protective immunity.
\end{abstract}

Conflict of interest: DEG is a member of the GlaxoSmithKline Vaccines Research and Development Advisory Board.

Copyright: () 2020, American Society for Clinical Investigation.

Submitted: November 13, 2019

Accepted: January 8, 2020

Published: February 13, 2020

Reference information: /CI Insight. 2020;5(3):e134992.

https://doi.org/10.1172/jici.

insight.134992.

\section{Introduction}

Despite the availability of safe and highly effective live attenuated measles virus $(\mathrm{MeV})$ vaccines, measles continues to be a significant, and recently increasing, cause of morbidity and mortality, with more than 100,000 deaths each year $(1,2) . \mathrm{MeV}$ is a highly infectious, negative-strand RNA virus transmitted by aerosol or respiratory droplets that causes a systemic rash disease in both humans and nonhuman primates (3, 4). $\mathrm{MeV}$ replicates in multiple types of cells including lymphocytes, monocytes, epithelial cells, and endothelial cells $(5,6)$, with efficient transmission to susceptible individuals for several days before and after the onset of the rash (7). The rash appears 10-14 days after infection and coincides with the appearance of the adaptive immune response, clearance of infectious virus, and clinical recovery (8). Despite the elimination of infectious virus, MeV RNA persists in PBMCs, urine, and nasopharyngeal secretions of children with measles for at least 3-4 months $(9,10)$.

Detailed studies of rhesus macaques experimentally infected with WT MeV demonstrated that clearance of viral RNA from PBMCs occurs in 3 phases $(8,11)$. After an initial peak on days $7-10$, there is a rapid decline coincident with the clearance of infectious virus (10-14 days), followed by up to a 10-fold rebound (14-24 days), and then a slow decline to undetectable levels 30-90 days after infection. After clearance from PBMCs, viral RNA is still detected in lymphoid tissues (8).

The host immune response to $\mathrm{MeV}$ is essential for viral clearance, clinical recovery, and the establishment of life-long immunity (12). Measles is accompanied by a robust immune response; and, in general, the cellular immune response is most important for clearance, whereas the humoral immune response is most important for protection against reinfection (13-16). MeV-specific IgM is detected after rash onset and maintained for approximately 28 days $(17,18)$, and serves as a marker of primary infection. MeV-specific IgG responses appear 2-3 weeks after infection, increase in amount and avidity 

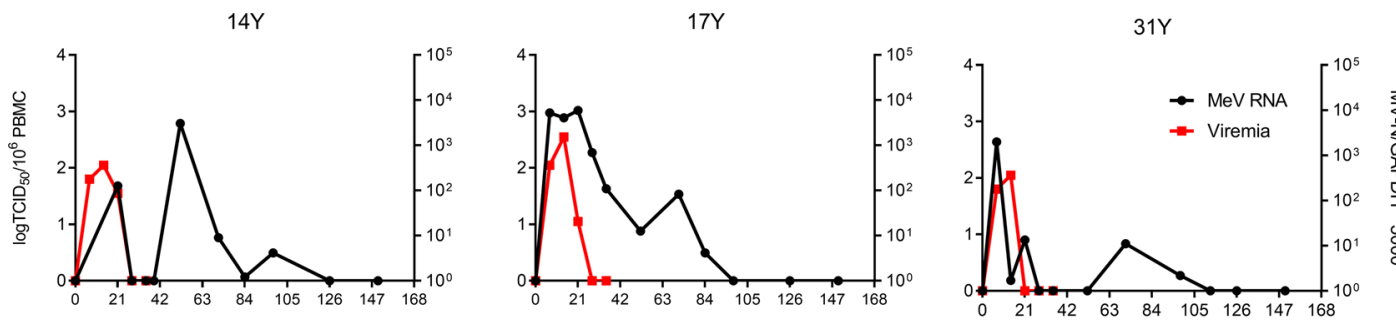

$46 \gamma$
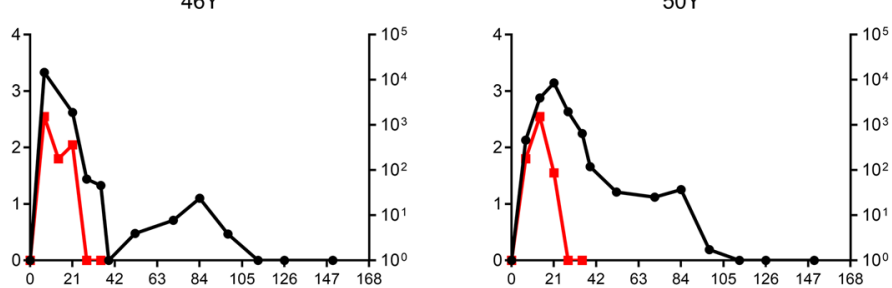

$31 x$

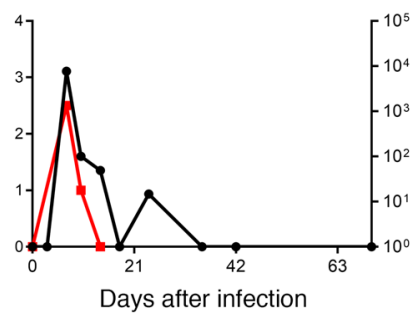

$42 X$

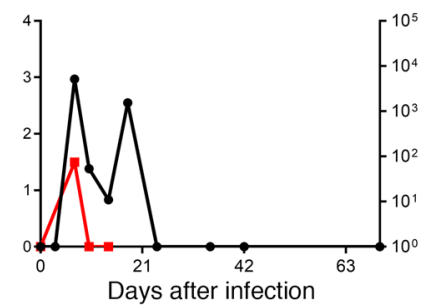

$46 \mathrm{X}$

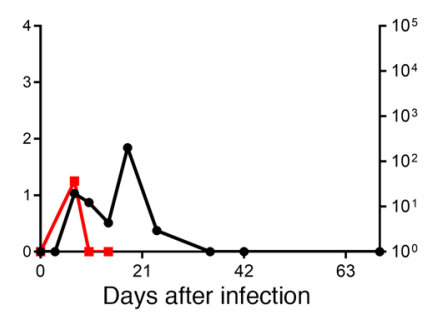

Figure 1. Prolonged presence of viral RNA in PBMCs. Macaques were infected intratracheally with the WT Bilthoven strain of measles virus (MeV). Viremia was measured by cocultivation of serially diluted PBMCs on Vero/hSLAM cells and data from individual macaques are presented as the log(T$\left.\mathrm{CID}_{50}\right) / 10^{6}$ PBMCs (red lines). MeV N gene RNA in PBMCs was measured by qRT-PCR (black lines). Assays were run in duplicate with a standard of $1 \times 10^{1}$ to $1 \times 10^{8}$ copies of MeV RNA. MeV RNA load was normalized to GAPDH. Results are expressed as [(MeV N RNA copies)/(GAPDH RNA copies)] $\times 5000$.

over time (19), and are maintained for life (20), but the mechanisms for establishing life-long protective immunity have not been defined.

$\mathrm{MeV}$ has 6 structural proteins: the hemagglutinin $(\mathrm{H})$ and fusion $(\mathrm{F})$ surface glycoproteins, the matrix $(\mathrm{M})$ protein, the nucleocapsid $(\mathrm{N})$ protein, phosphoprotein $(\mathrm{P})$, and large polymerase protein $(\mathrm{L})$. The most rapidly produced antibodies are against the $\mathrm{MeV} \mathrm{N}$ protein, and the absence of $\mathrm{N}$-specific antibodies is used as an indicator of measles seronegativity $(21,22)$. Antibodies against the $\mathrm{H}$ and $\mathrm{F}$ surface glycoproteins are important for virus neutralization and protection from infection $(23,24)$.

Unlike infection with WT MeV, protective immunity induced by the live attenuated $\mathrm{MeV}$ vaccine may not be life-long and waning immunity with secondary vaccine failure can occur (25-28). Understanding the mechanisms involved in the generation and maintenance of life-long protective immunity to measles is thus critical for assessing the challenges of achieving and sustaining measles elimination through vaccination (29). To that end, we have characterized the cell type-specific sites of viral RNA persistence and evolution of the MeV-specific antibody response in rhesus macaques over 6 months after WT MeV infection. We have identified ongoing changes in lymphoid tissue architecture, $\mathrm{T}$ follicular helper (Tfh) cells in circulation, and the frequencies of MeV-specific antibody-secreting cells (ASCs) in lymphoid tissue, PBMCs, and $\mathrm{BM}$ associated with persistence of MeV RNA. These studies suggest that persistent viral RNA and protein within lymphoid tissue promotes prolonged maturation and maintenance of the $\mathrm{MeV}$-specific neutralizing antibody response and life-long protective immunity.

\section{Results}

MeV RNA persistence in immune cells. A total of 13 juvenile male rhesus macaques were infected intratracheally with $\mathrm{WT} \mathrm{MeV}$ in 3 groups (cohort $\mathrm{X}=3, \mathrm{Y}=5, \mathrm{U} / \mathrm{V}=5$ ). PBMCs were assessed for infectious virus by cocultivation on Vero/hSLAM cells and MeV RNA by qRT-PCR for the MeV N gene. All 
A

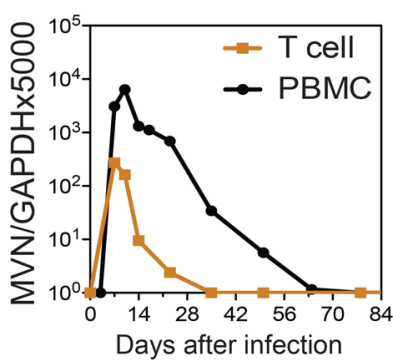

B

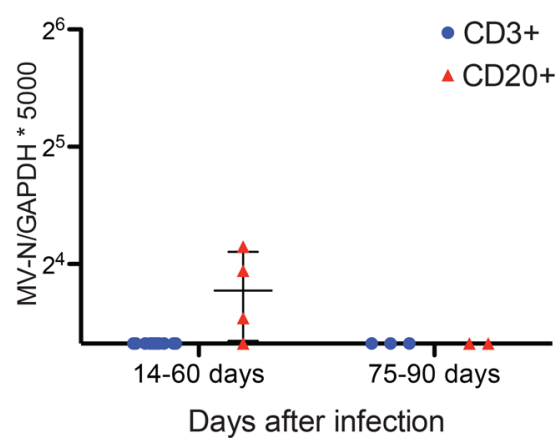

$46 \mathrm{U}$

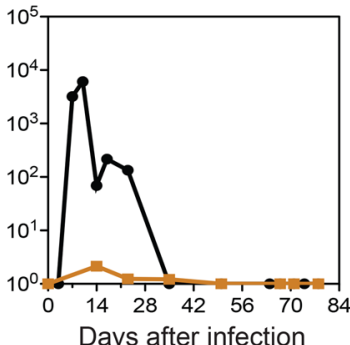

C

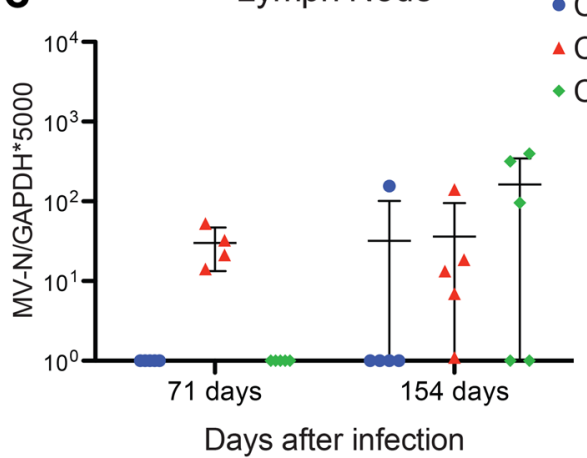

$67 \mathrm{U}$

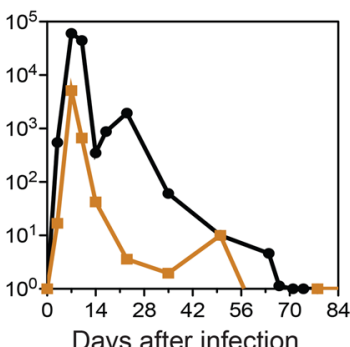

$40 \mathrm{~V}$

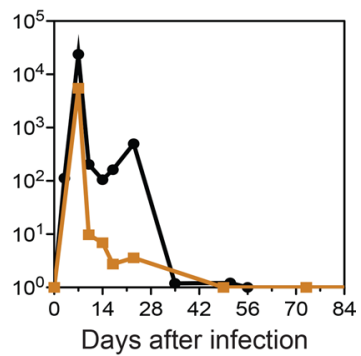

- CD3+

$\triangle \mathrm{CD} 20+$

CD14+

Figure 2. Detection of MeV RNA in immune cells. Mononuclear cells from peripheral blood (A and $\mathbf{B}$ ) and inguinal lymph nodes (C) were isolated and assessed for presence of measles virus (MeV) N gene RNA by qRT-PCR ( $\mathbf{A}$ and $\mathbf{C}$ ) or ddRT-PCR (B). (A) MeV N gene RNA was quantified in total PBMCs and isolated CD3 ${ }^{+}$ T cells from 4 individual animals (15U, 46U, 67U, 40V). (B) MeV N gene RNA was quantified in quadruplicates by ddRT-PCR in PBMCs collected from $Y$ monkeys 14-60 and 75-90 days after infection that had been sorted into $\operatorname{CD3}^{+}(n=11 ; n=4$, respectively) and $\operatorname{CD2O}(n=4 ; n=2$ respectively) subsets. (C) MeV N gene RNA was quantified in duplicate by qRT-PCR in lymph node cells collected from Y monkeys 71 and 154 days after infection that had been sorted into CD3 ${ }^{+}$, CD20 $(n$ $=4$ at 71 days after infection), and CD14+ subsets. Numbers of animals studied vary between assays because sufficient cells were not available to perform all assays on all animals. Data are presented as (copies of MeV-N/copies of GAPDH) $\times 5000$ for individual animals in dot plots with mean \pm SD indicated.

macaques developed a viremia 7-10 days after infection and a rash that appeared on days 10-11. Infectious virus was cleared by day 14, with persistent MeV RNA in PBMCs that gradually decreased to undetectable levels 30-90 days after infection (Figure 1 and refs. 8, 11).

To determine whether $\mathrm{CD}^{+} \mathrm{T}$ cells were the primary sites of MeV RNA persistence in PBMCs, levels of RNA in isolated $\mathrm{CD}^{+} \mathrm{T}$ cells were compared with levels in the total PBMC population by qRT-PCR for the $\mathrm{MeV} \mathrm{N}$ gene (Figure $2 \mathrm{~A}$ ). $\mathrm{CD}^{+} \mathrm{T}$ cells accounted for only a small proportion of the $\mathrm{MeV}$ RNA present in PBMCs. To further identify the cell types in which MeV RNA persists after clearance of infectious virus, PBMCs (Figure 2B) and inguinal lymph node mononuclear cells (Figure 2C) were sorted with magnetic beads into B cell, T cell, and monocyte populations, and digital droplet (dd) RT-PCR (PBMCs) or qRT-PCR (lymph node cells) was used to detect viral RNA. In PBMCs, MeV RNA was present primarily in $\mathrm{CD} 20^{+} \mathrm{B}$ cells up to 60 days after infection (Figure $2 \mathrm{~B}$ ). In lymph nodes, $\mathrm{MeV}$ RNA was detected in $\mathrm{CD} 20^{+} \mathrm{B}$ cells on day 71 as well as in $\mathrm{CD}^{+}$and $\mathrm{CD} 14^{+}$(monocyte/macrophages) cells on day 154, in addition to CD20 cells of some animals (Figure 2C). Therefore, B cells were the most frequent cells, but not the only immune cell, in which MeV RNA persisted. MeV RNA was rarely detected in BM mononuclear cells (Table 1).

Development of the MeV-specific antibody response. Dynamics of the MeV-specific antibody response development were characterized through 6 months after infection (Figure 3). IgM was detected in plasma by day 14 , reached a maximum on day 21 , and decreased by day 28 (Figure $3 \mathrm{~A}$ ). MeV-specific IgG binding and neutralizing antibodies appeared in plasma 2-3 weeks after infection, reached maximum titers by day 21 , and were sustained at elevated levels through 6 months, the last time point tested (Figure 3B). To further define the $\mathrm{MeV}$ protein specificity of these antibodies, antigen-specific ELISAs for the $\mathrm{MeV} \mathrm{H}, \mathrm{N}$, and $\mathrm{F}$ proteins were performed. All macaques developed antibodies against all 3 structural proteins (Figure 3C). Antibody responses specific for the $\mathrm{N}$ protein were most rapid and abundant, followed by $\mathrm{H}$, and then $\mathrm{F}$, and all of them were sustained for the 6 months evaluated. 
Table 1. Detection of measles virus $\mathbf{N}$ gene RNA by ddRT-PCR in BM mononuclear cells from 5 Y group rhesus macaques

\begin{tabular}{ccc}
\hline Day after infection & No. positive/total no. sampled & MeV N gene/GAPDH copies $\times \mathbf{5 0 0 0}$ \\
\hline 14 & $0 / 5$ & $\mathrm{NA}$ \\
28 & $1 / 5$ & $0.85 \times 10^{2}$ \\
39 & $1 / 5$ & $0.825 \times 10^{1}$ \\
60 & $0 / 5$ & $\mathrm{NA}$ \\
84 & $1 / 5$ & $5.5 \times 10^{2}$ \\
\hline
\end{tabular}

Because the quality of the antibody response is important for protection from infection (30), antibody avidity was also assessed. Maturation of the antibody response was slow, as avidity did not peak until 98 days after infection (Figure 3D). On day 28, when $\mathrm{MeV}$ antibody avidity was low, avidity was highest for antibody against the $\mathrm{H}$ and $\mathrm{N}$ proteins. Although avidity of antibody against all evaluated proteins, including $\mathrm{F}$, improved later, the highest avidity antibody continued to have specificity for the $\mathrm{H}$ and $\mathrm{N}$ proteins (Figure $3 \mathrm{E}$ ), with the mean avidity to $\mathrm{H}$ higher than to $\mathrm{F}$ (mean $\pm \mathrm{SD} ; \mathrm{H}, 0.964 \pm 0.214$ vs. F, $0.200 \pm 0.274$; adjusted $P<0.001)$.

To further characterize development of the humoral response, we examined the appearance of ASCs in lymph nodes, PBMCs, and BM using B cell ELISpot assays. MeV-specific ASCs were present in lymph nodes 35 days after infection, with an increase on day 70 (Figure 4A). In PBMCs, MeV-specific ASCs were detected by 14 days after infection, with increases on weeks $3\left(27.2 \pm 55.3 \mathrm{ASCs} / 10^{6} \mathrm{PBMCs}\right)$ and 7 (751.5 \pm 1070 ASCs $/ 10^{6}$ PBMCs) and continuous entry into circulation for at least 5 months after infection (Figure 4B). During the rash, when MeV-specific ASCs appeared in circulation and began to increase, a 10-fold increase in numbers of total ASCs was also noted (Figure 4B). This increase in total ASCs in relation to baseline and to $\mathrm{MeV}$-specific ASCs was analyzed in more detail in an additional 4 macaques 1-6 weeks after infection (Figure 4, C and D). Total ASCs in blood increased 20- to 100-fold 2-3 weeks after infection compared with $\mathrm{MeV}$-specific ASCs, suggesting a general effect of $\mathrm{MeV}$ infection on appearance of non-MeV-specific ASCs in the bloodstream during resolution of the rash.

Because BM plasma cells are the source of most plasma antibody $(31,32)$, we also assessed the appearance of ASCs in the BM at 2- to 4-week intervals after infection (Figure 4E) for the same animals analyzed in Figure 4B. MeV-specific ASCs were detected by day 14, with an increase 28 days after infection (mean $\pm \mathrm{SD} ; 1032 \pm 270 \mathrm{ASCs} / 10^{6} \mathrm{BM}$ mononuclear cells) and a sustained presence thereafter (Figure $4 \mathrm{E}$ ). This pattern was confirmed in 3 additional macaques sampled 14, 35, and 100 days after infection (Figure 4F).

Because antibody against the $\mathrm{H}$ glycoprotein is most important for virus neutralization and correlates best with protection from infection $(22,23,33)$, we examined the specificity of the antibody produced by ASCs in various compartments for the X monkeys. On day 70, lymph nodes of 2 animals had equal numbers of $\mathrm{H}$ - and $\mathrm{N}$-specific ASCs, whereas the third had more $\mathrm{H}$ - than $\mathrm{N}$-specific ASCs (Figure 5A). At the same time, ASCs in PBMCs of 2 animals had equal numbers of $\mathrm{H}$ - and $\mathrm{N}$-specific ASCs, whereas the remaining 2 had more $\mathrm{H}$ - than N-specific ASCs (Figure 5B). Although $\mathrm{H}$ - and N-specific ASCs were fairly equally represented in the lymph nodes and blood, analysis of the specificity of the BM ASCs showed an increasing proportion producing antibody against $\mathrm{H}$ through 100 days after infection (Figure 5, C and D). Therefore, the production of ASCs by lymph nodes with persistent MeV RNA (Figure 2C) resulted in sustained circulation of MeV-specific ASCs through 6 months after infection, with an apparent preferential accumulation of $\mathrm{H}$-specific ASCs in BM (Figure 5).

Germinal center formation in lymph nodes. To assess changes in the lymph nodes that harbored $\mathrm{MeV}$ RNA (Figure 2) relevant to continuous production of ASCs (Figure 4 and Figure 5), we compared the morphology in lymph node tissues collected from uninfected macaques with infected macaques on days 71-72 and days 154-155 after infection (Figure 6). The presence of germinal centers (GCs), the sites of ASC production, was evaluated by staining sections with hematoxylin and eosin. Infected animals had enlarged reactive lymph nodes and the numbers of GCs increased over time (Figure 6, A and C). Immunohistochemical staining showed that Ki-67-positive proliferating cells were abundant within GCs at both times after infection (Figure 6B). Ten weeks after infection, there was an average of 5 GCs within a lymph node section. And by week 22, the average number of GCs had increased to 
A MeV-specific IgM
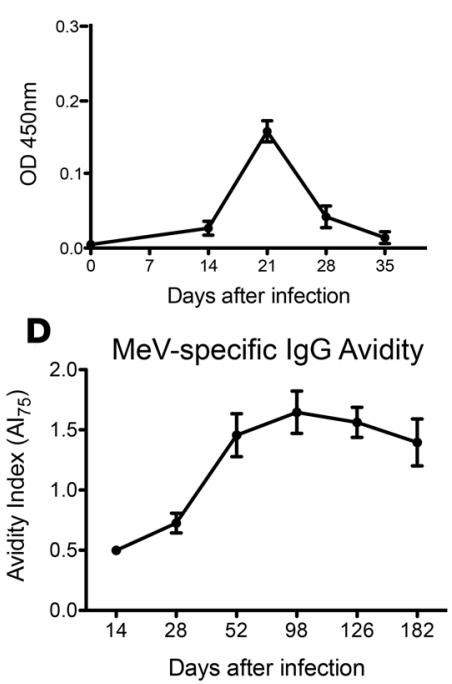

B $\mathrm{MeV} \operatorname{lgG}$ and Neutralization

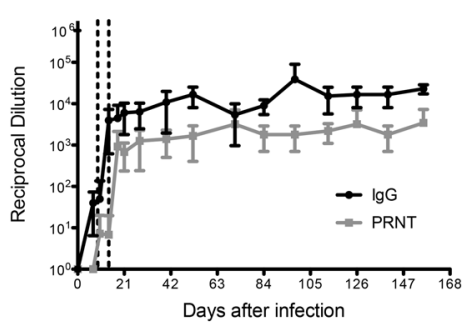

E

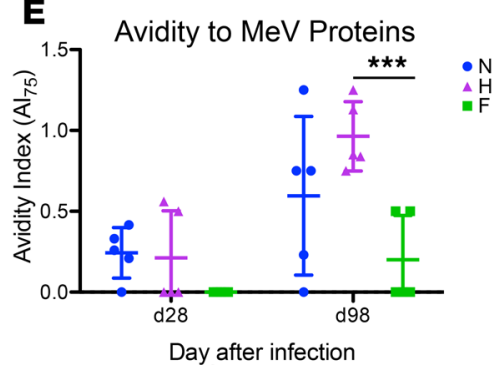

$\underset{\mathrm{H}}{\mathrm{H}}$

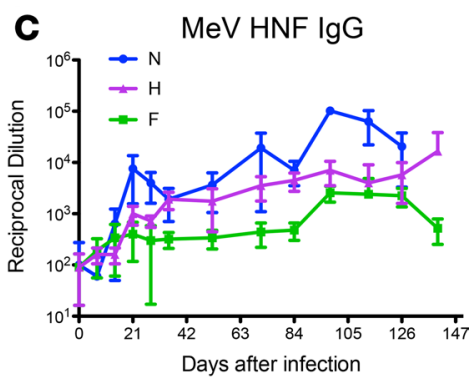

Days after infection

Figure 3. Antibody production after primary WT MeV infection. Plasma samples from $5 \mathrm{Y}$ group macaques were examined for measles virus-specific (MeV-specific) IgM (A) and IgG (B, black line) by enzyme immunoassay (EIA) using MeV-infected cell lysate as antigen. Neutralizing antibody was measured with a plaque reduction neutralization assay using the Edmonston strain of $\mathrm{MeV}$ on Vero cells (B, gray line). Dotted vertical lines indicate the period of the rash. (C) Antibodies specific for the $\mathrm{H}$ (purple triangle), $\mathrm{N}$ (blue circle), and $\mathrm{F}$ (green square) MeV proteins were measured by EIA. (D and E) Avidity of MeV-specific IgG was determined by measuring the concentration of $\mathrm{NH}_{4} \mathrm{SCN}$ needed to disrupt antigen-antibody interaction. An avidity index $75 \%$ ( $\mathrm{Al}_{75}$ ) was calculated for interaction of antibody with $\mathrm{MeV}(\mathbf{D})$ and with $\mathrm{H}, \mathrm{N}$, and $\mathrm{F}(\mathbf{E})$ as the concentration of $\mathrm{NH}_{4} \mathrm{SCN}$ required to remove $75 \%$ of bound antibody. In $\mathbf{A}$ and $\mathbf{D}$, data are presented as mean $\pm \mathrm{SD}$; bar indicates the mean. ${ }^{* *} P<0.001$ as determined by 2 -way mixed-effects model ANOVA with Tukey's post hoc analysis.

a variable degree for all 3 animals examined at both time points (Figure 6C), whereas no GCs and few Ki-67-positive cells were identified in lymph nodes from uninfected macaques (Figure 6D).

By week 22, some GCs had become hyalinized, a process by which cells and collagen fibers take on a homogeneous, acellular, "glassy" appearance (Figure 7, A and B). The mean number of hyalinized GCs per lymph node, identified by Mason's trichrome staining, after infection increased from less than 1 on day 71 to approximately 4 on day 154 (Figure 7C), representing an increase in the percentage of hyalinized GCs from a mean of $5 \%$ on day 71 to $16.3 \%$ on day 154 (Figure 7D). For both numbers of GCs (Figure 6C) and hyalinized GCs (Figure 7, C and D), 14Y had a less dramatic change over time than 17Y and 31Y. One difference of unknown importance is that $14 \mathrm{Y}$ received vitamin $\mathrm{A}$ at the time of the rash, whereas $17 \mathrm{Y}$ and $31 Y$ did not. Further study of the effect of vitamin A on the immune response to measles may be of interest. Lymph node sections were also stained for $\mathrm{CD}^{+}$and $\mathrm{CD} 20^{+}$cells to characterize the distribution of $\mathrm{T}$ cells and $\mathrm{B}$ cells on day 154 after infection (Figure 7E). CD20+ cells were mainly present in GCs, whereas CD3 ${ }^{+}$ cells were mostly present in the paracortex.

Peripheral Tfh cells steadily increased after infection. Tfh cells are a subset of CD4+ $\mathrm{T}$ cells that play a key role in GC reactions and are essential for B cell proliferation, affinity maturation, and the generation of long-lived memory B cells and antibody-secreting plasma cells (34). In lymphoid tissues, Tfh cells are recognized phenotypically by their expression of CXCR5, ICOS, Bcl-6, and PD-1 and functionally by their synthesis of IL-21 that drives plasma cell differentiation (34-37). Although Tfh cells predominantly mediate their function in the lymph node, they are also found in the peripheral circulation (pTfh cells). Several lines of evidence suggest that circulating $\mathrm{CXCR} 5^{+} \mathrm{CD} 4^{+}$cell populations include memory cells committed to the Tfh lineage that are generated from and share functional properties with GC Tfh cells but no longer express ICOS or Bcl-6 (38-40). Therefore, we evaluated the expression of CXCR5 on MeV H and N-specific $\mathrm{CD}^{+} \mathrm{T}$ cells (Figure 8$)$. H-specific $\mathrm{CD} 4^{+} \mathrm{CXCR} 5^{+} \mathrm{T}$ cells increased after infection $(0.65 \% \pm 0.28$ on day 39 to $2.61 \% \pm 0.69$ on day 113 ) (Figure $8 \mathrm{~A}$ ). $\mathrm{N}$-specific $\mathrm{CD} 4^{+} \mathrm{CXCR} 5^{+} \mathrm{T}$ cells also increased over time after infection $(0.47 \% \pm 0.09$ on day 39 to $3.97 \% \pm 1.63$ on day 113$)$.

Next, we examined the coexpression of CXCR5 and PD-1 on MeV-specific CD4 ${ }^{+} \mathrm{T}$ cells. There was an increase in $\mathrm{H}$ - and $\mathrm{N}$-specific $\mathrm{CD} 4^{+} \mathrm{CXCR} 5^{+} \mathrm{PD}-1^{+} \mathrm{T}$ cells over time (Figure $8, \mathrm{~B}$ and $\mathrm{D}$ ). However, very little IL-21 production could be detected by intracellular cytokine staining (Figure 8C). Therefore, $\mathrm{MeV}$ infection resulted in an increase in $\mathrm{MeV}$-specific circulating pTfh cells for at least 4 months after infection. 
A MeV Lymph node
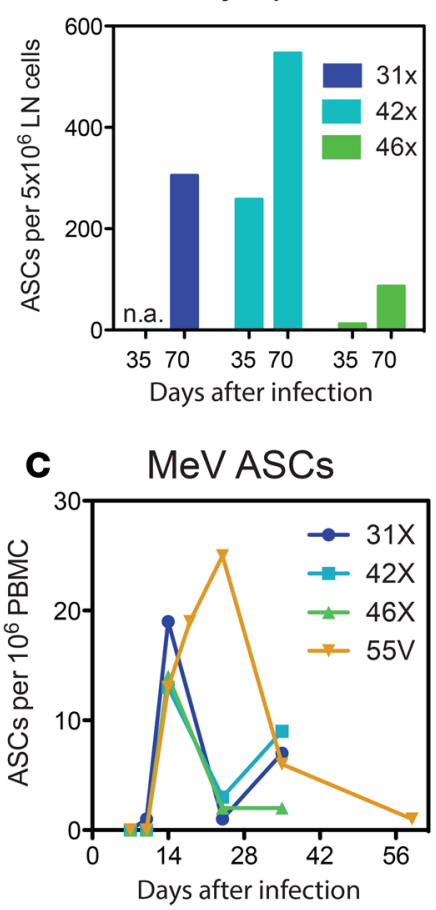

E Bone marrow

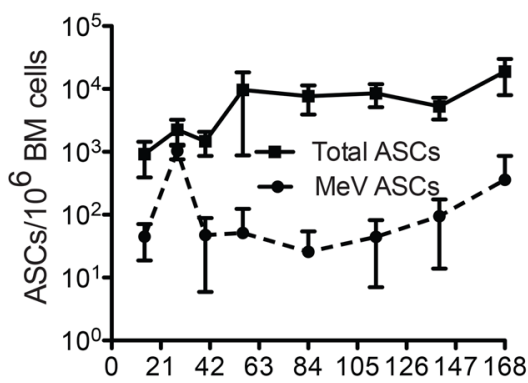

Days after infection
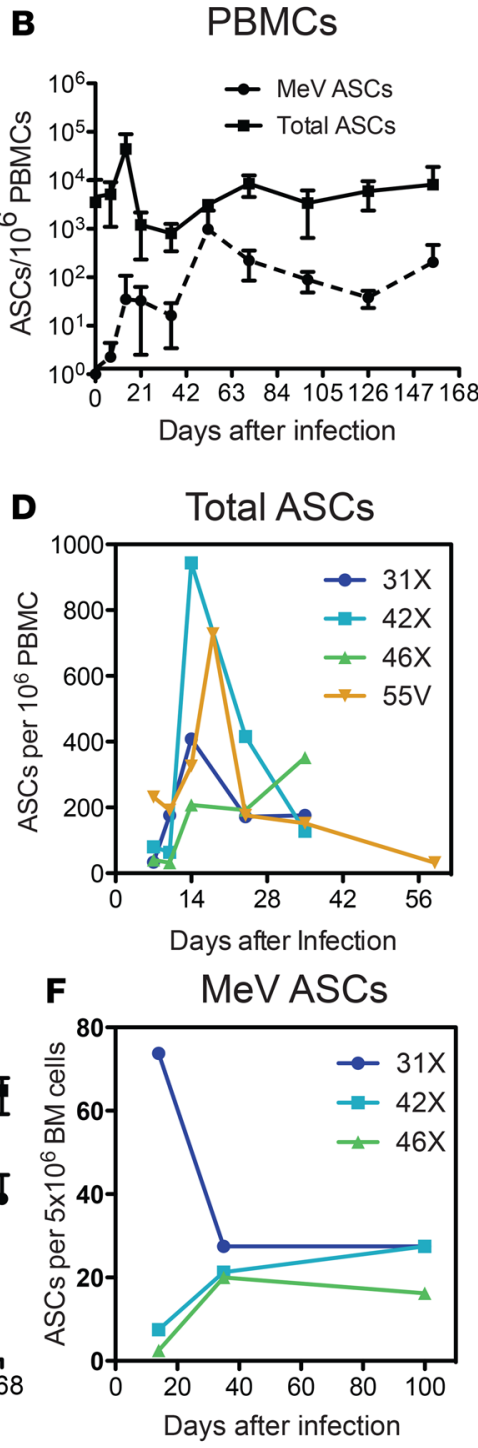

Figure 4. Prolonged production of antibody-secreting cells. Numbers of measles virus-specific (MeV-specific) or total antibody-secreting cells (ASCs) present in inguinal lymph nodes (A), PBMCs (B-D), and BM (E and F) at the indicated days after infection were measured by ELISpot assays. Plates were coated with MeV lysate (MeV-specific ASCs) or anti-monkey IgG, IgA, IgM (total ASCs) and $5 \times 10^{6}$ cells were added to each well. All samples were run in duplicate and data plotted as number of ASCs for individual $X$ group macaques $(\mathbf{A}, \mathbf{C}, \mathbf{D}$, and $\mathbf{F})$ or mean $A S C s \pm S D$ per $1 \times 10^{6}$ PBMCs (B) or BM mononuclear cells (E) for $5 \mathrm{Y}$ group macaques.

\section{Discussion}

In this study, we used a rhesus macaque model of primary WT MeV infection to characterize the development of long-lived antibody-dependent protective immunity and the association of this development process with prolonged presence of viral RNA in subsets of immune cells for 6 months after acute infection. MeV RNA was most consistently detected in B cells in both PBMCs and lymph nodes after clearance of infectious virus but was occasionally detected in $\mathrm{T}$ cells and monocytes several months after infection. Infection induced rapid production of $\mathrm{MeV}$-specific antibodies against multiple viral proteins, whereas avidity maturation of the virus-specific antibodies occurred over months. During this period of antibody maturation, lymph node GC B cells proliferated and GCs increased in number. Two to 3 weeks after infection, MeV-specific pTfh cells and ASCs were detected in blood, with an accompanying burst of circulating ASCs that were not producing antibody against $\mathrm{MeV}$. Although similar numbers of ASCs with specificity for $\mathrm{H}$ and $\mathrm{N}$ were produced in lymphoid tissue and entered the circulation, ASCs in the BM were more likely to be producing antibody against the $\mathrm{H}$ glycoprotein than the $\mathrm{N}$ protein. Together, these data suggest that persistence of WT MeV RNA in 
A

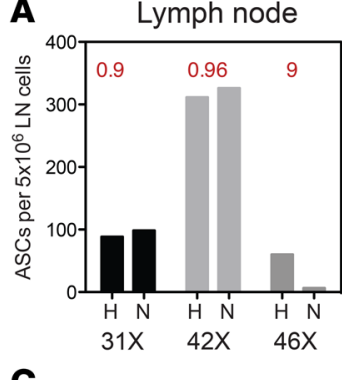

C

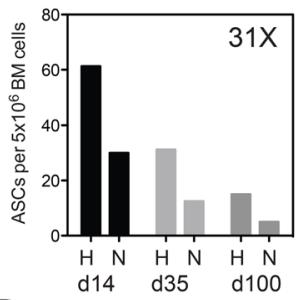

D

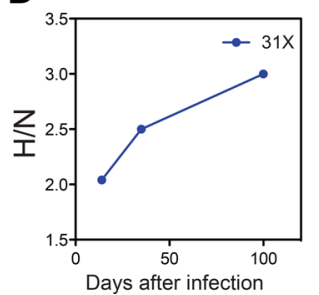

B

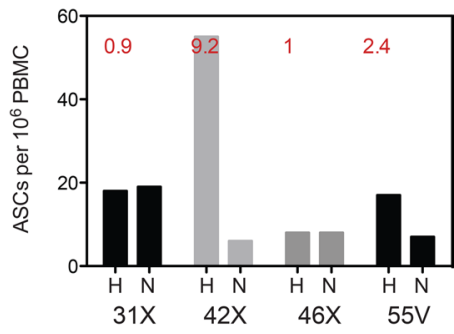

Bone marrow
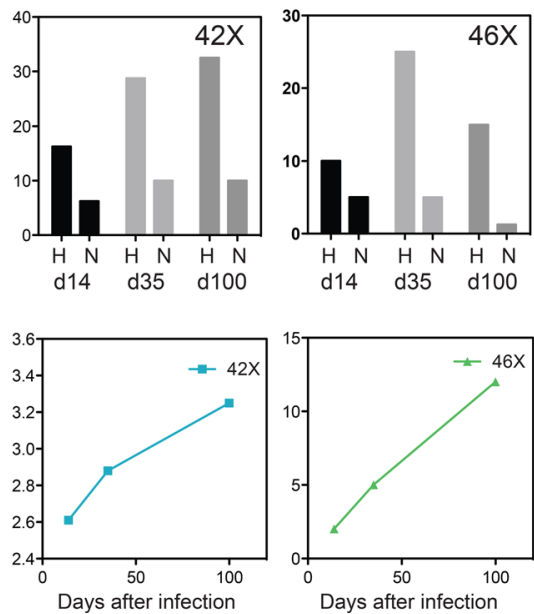

Figure 5. MeV protein specificity of antibody-secreting cells in different compartments. Relative numbers of IgG-producing antibody-secreting cell (ASCs) specific for $\mathrm{H}$ and $\mathrm{N}$ proteins were measured by ELISpot assays using plates coated with lysates of measles virus (MeV) $\mathrm{H}$-expressing $\mathrm{L}$ cells or baculovirus-expressed $\mathrm{N}$ protein. Inguinal lymph node ASCs (A) and PBMC ASCs (B) from 3 to 4 individual macaques were assessed on day 70 after infection. Ratios of $\mathrm{H}$ - to $\mathrm{N}$-specific ASCs are indicated in red. BM cell ASCs from 3 macaques (31X, 42X, 46X) were assessed 14, 35, and 100 days after infection, with data shown as numbers of cells from individual assays (C) and as a ratio of $\mathrm{H}$-specific to $\mathrm{N}$-specific ASCs (D). L, large polymerase protein; N, nucleocapsid, H, hemagglutinin and N, nucleocapsid.

lymphoid tissue drives $\mathrm{MeV}$ protein production and ongoing antigenic stimulation to promote the progressive development of high-quality, long-lived plasma cells responsible for the lifelong maintenance of MeV-specific neutralizing antibodies and protective immunity.

WT MeV infects many different types of cells, but cells of the immune system that express the $\mathrm{MeV}$ receptor CD150/SLAM are particularly important for systemic spread and alterations in immunity due to infection (41). Studies of macaques infected with MeV expressing EGFP and children with measles have shown that $\mathrm{MeV}$ infects memory $\mathrm{T}$ cells and both memory and naive $\mathrm{B}$ cells during the acute phase of infection $(42,43)$. Although these populations are transiently depleted during $\mathrm{MeV}$ infection, infected immune cells are not eliminated and MeV N gene RNA can be detected in PBMCs for 30-90 days and within the lymph node for at least 6 months after infection (Figure 2C) (8). Sequences from viral RNA recovered 3-4 months after rash onset are identical to the original infecting virus (10). Thus, although the state of the persistent RNA is unclear, the prolonged presence of MeV RNA in tissues is attributable to slow clearance rather than acquisition of escape mutations. In the current study, we determined that MeV RNA persists primarily in B cells, but also in T cells and monocytes in PBMCs and lymph nodes, but was rarely detected in BM. However, the nature and intracellular localization of this viral RNA and the time of its eventual clearance are not known.

Viral RNA persistence is likely a common feature of acute RNA viral infections $(8-10,44-48)$ and occasionally leads to reactivation, progressive disease (e.g., subacute sclerosing panencephalitis for $\mathrm{MeV}$ ), and/or unexpected transmission of infectious virus (e.g., filoviruses, arenaviruses, flaviviruses, alphaviruses) $(45,49-56)$ months or years after apparent recovery from the acute disease. However, viral RNA persistence may also provide benefit to the host through ongoing synthesis of viral antigens that stimulate progressive maturation of the antiviral immune response to establish long-term protective immunity (11). 


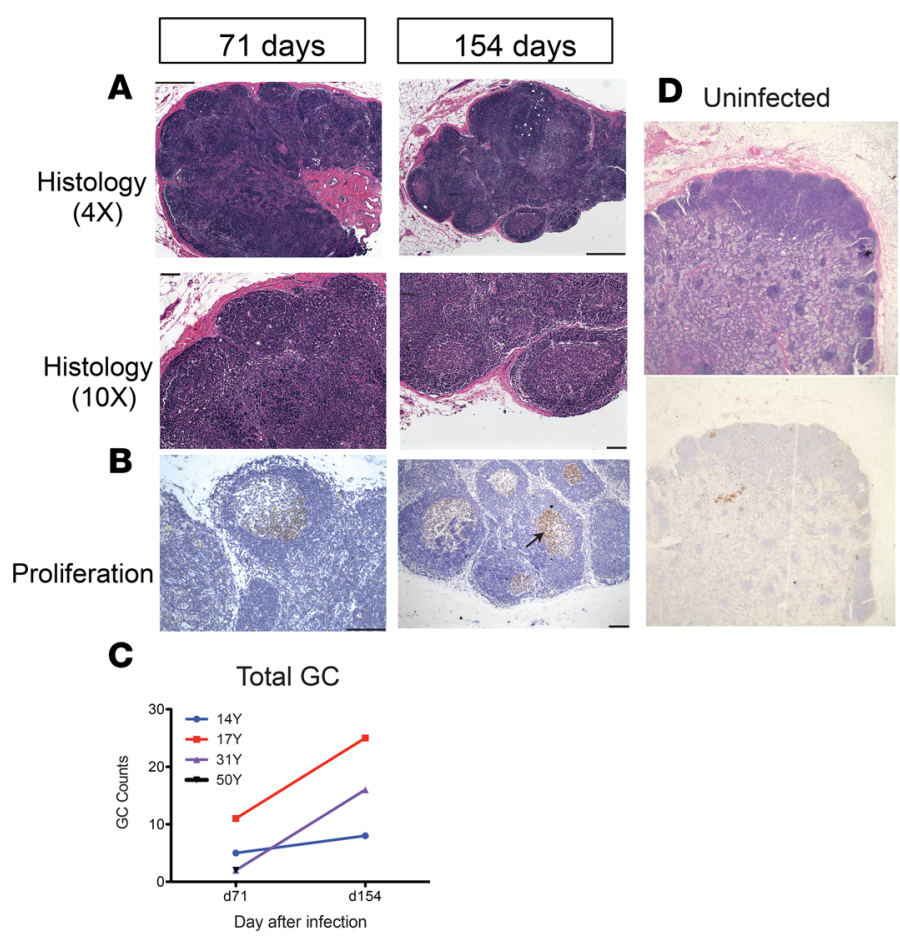

Figure 6. Lymph node germinal center histopathology. Inguinal lymph node biopsies from uninfected macaques and measles virus-infected (MeV-infected) macaques $71(n=4)$ and $154(n=3)$ days after infection. Tissues were fixed, embedded in paraffin, sectioned, and stained with $H \& E$ (A and $\mathbf{D})$ and for expression of Ki-67 indicative of cell proliferation (black arrow; B). Representative sections from $14 \mathrm{Y}$ (A) and 31Y (B) and an uninfected control macaque (magnification: $\times 4$ objective; $\times 10$ eyepiece) (D) are shown. Counts of germinal centers /lymph node section are indicated for $4 \mathrm{MeV}$-infected macaques from day 71 and $3 \mathrm{MeV}$-infected macaques from day 154 (C). 50Y data for d154 were not available and the d71 count is superimposed on data from 31Y. Scale bars: $2 \mu \mathrm{m}$ (A: top panels; B: left panel) $100 \mu \mathrm{m}$ (A: bottom panels; B: right panel)

Lymphoid tissues are major sites of $\mathrm{MeV}$ systemic replication, and during the acute phase of measles, there is lymphopenia and depletion of cells in lymphoid tissue. This phase is followed by repopulation and proliferation of cells during the appearance of the adaptive immune response and rash (3, 42, $57,58)$. In the current study, we have shown that after resolution of the acute rash disease, there was a continued increase in formation of GCs and proliferation of B cells in lymphoid tissue for at least 6 months. This differs from GC formation observed after immunization with soluble protein antigens (59), where GCs are present in draining lymph nodes for only 2-3 weeks. Long-term maintenance of GCs has been observed with chronic viral infections of mice, humans, and macaques (59-65), so although infectious virus is eliminated quickly, persistence of $\mathrm{MeV}$ RNA is associated with GC responses similar to those observed with chronic infection. Hyalinization of reactive GCs, observed late after $\mathrm{MeV}$ infection, has also been described with chronic infection $(61,66)$.

There is increasing evidence that the affinity of antibodies induced by infection or immunization is important for protective immunity. For instance, vaccination with inactivated $\mathrm{MeV}$ that leads to production of low affinity antibodies is associated with primary vaccine failure and the production of immune complexes and enhanced disease after infection $(28,30,67)$. Affinity maturation occurs in GCs through a balance between elimination of lower affinity clones and variants leading to GC homogeneity and loss of clonal diversity (68). This process is facilitated by the ability of follicular DCs to retain antigen for B cell selection and prolonged GC reactions $(59,69)$. Affinity maturation is dependent on help for B cells within GCs from stromal and Tfh cells producing IL-6, IL-21, APRIL, and CXCL12 (34, 36, 70-73). WT MeV infection induced a gradual increase in circulating virus-specific pTfh cells coincident with an increase in antibody avidity and continued production of ASCs. In HIV infection, Tfh cells increase in frequency and serve as cellular reservoirs for replication-competent virus $(34,74)$, but the ability of these cells to harbor persistent MeV RNA is not known.

During the ongoing development of GCs in secondary lymphoid tissue and affinity maturation of B cells, MeV-specific ASCs were continuously appearing in circulation, presumably trafficking to BM or tis- 
A

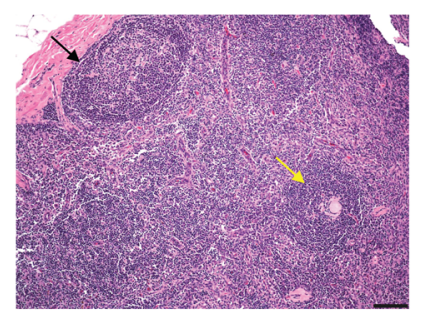

C Number hyalinized GCs

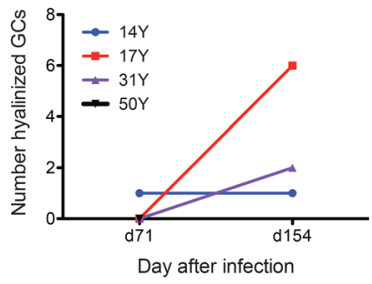

$\mathbf{E}$

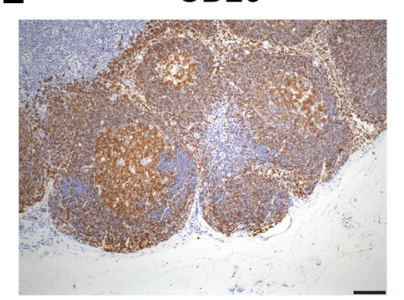

B

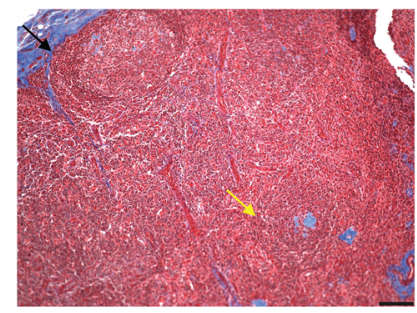

D Percent hyalinized GCs

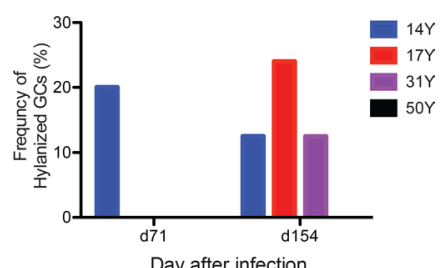

$\mathrm{CD} 3+$

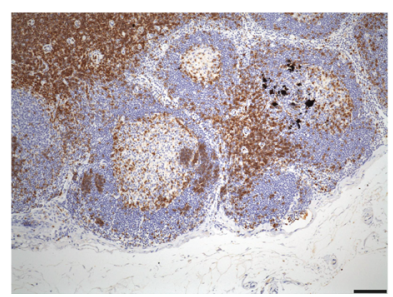

Figure 7. Germinal center hyalinization. Sequential sections from inguinal lymph node biopsies collected 71 and 154 days after infection were stained with H\&E (A) and Mason's trichrome stain (B) and examined for evidence of germinal center (GC) hyalinization. Representative normal (black arrows) and hyalinized (yellow arrows) GCs from day 154 are indicated. Numbers (C) and percentages (D) of hyalinized GCs/section are graphed for 3 macaques. For $50 Y$ tissue was available only for d71 and no hyalinized GCs were observed. (E) Representative sections from day 154 were stained for CD20+ B cells and CD3+ $\mathrm{T}$ cells. Scale bars: $100 \mu \mathrm{m}$.

sue sites of prior virus infection. This observation during acute $\mathrm{MeV}$ infection is in contrast to the response to immunization with a T-dependent antigen or inactivated vaccine, where, as with GC formation, ASCs are found in circulation for only 1-2 weeks (75-78). After respiratory syncytial virus infection, ASCs were detected in circulation for up to 2 months (79), but continued virus-specific ASC production for 6 months after an acute infection has not been previously described and likely reflects the continued activation of GCs in lymphoid tissue with persistent viral RNA.

During the first 2-3 weeks after $\mathrm{MeV}$ infection with the first appearance of MeV-specific ASCs, 20-100 times as many total ASCs, mostly producing antibody that is not against $\mathrm{MeV}$, also appear in circulation. These cells may represent the nonspecific stimulation of memory B cells (80) or the release of plasma cells from a finite number of BM niches to make room for plasma cells secreting antibody with a new specificity $(81,82)$. The latter explanation could result in the gradual decline of preexisting antibody titers and is consistent with the recently observed decrease in the diversity of antibody against other pathogens that occurs after measles (83).

ASCs present in the BM are the main contributors to plasma levels of antibody $(31,32)$. And after measles, ASCs secreting antibody against $\mathrm{H}$ were more likely to become established in BM than ASCs secreting antibody against $\mathrm{N}$ for all 3 animals examined, although similar numbers of $\mathrm{H}$ - and $\mathrm{N}$-specific ASCs were present in secondary lymphoid tissue for 2 of 3 animals and PBMCs for 2 of 4 animals. It remains unknown whether $\mathrm{H}$-specific ASCs are more likely to express receptors necessary for entering BM niches (e.g., CXCR4) or are more likely to express adhesive integrins or growth factor receptors (e.g., BCMA) necessary for survival as long-lived plasma cells after BM entry (70). Several properties of ASCs facilitate entry into BM niches (70), but antigen-dependent acquisition of these properties may be regulated by affinity maturation that tends to be higher for $\mathrm{H}$ than $\mathrm{N}$ or $\mathrm{F}$ (84). Most $\mathrm{MeV}$-neutralizing antibodies important for protection from reinfection (22) are directed against the $\mathrm{H}$ protein (23). Because of variability between animals, further study of larger numbers of animals will be necessary to confirm these observations, but 

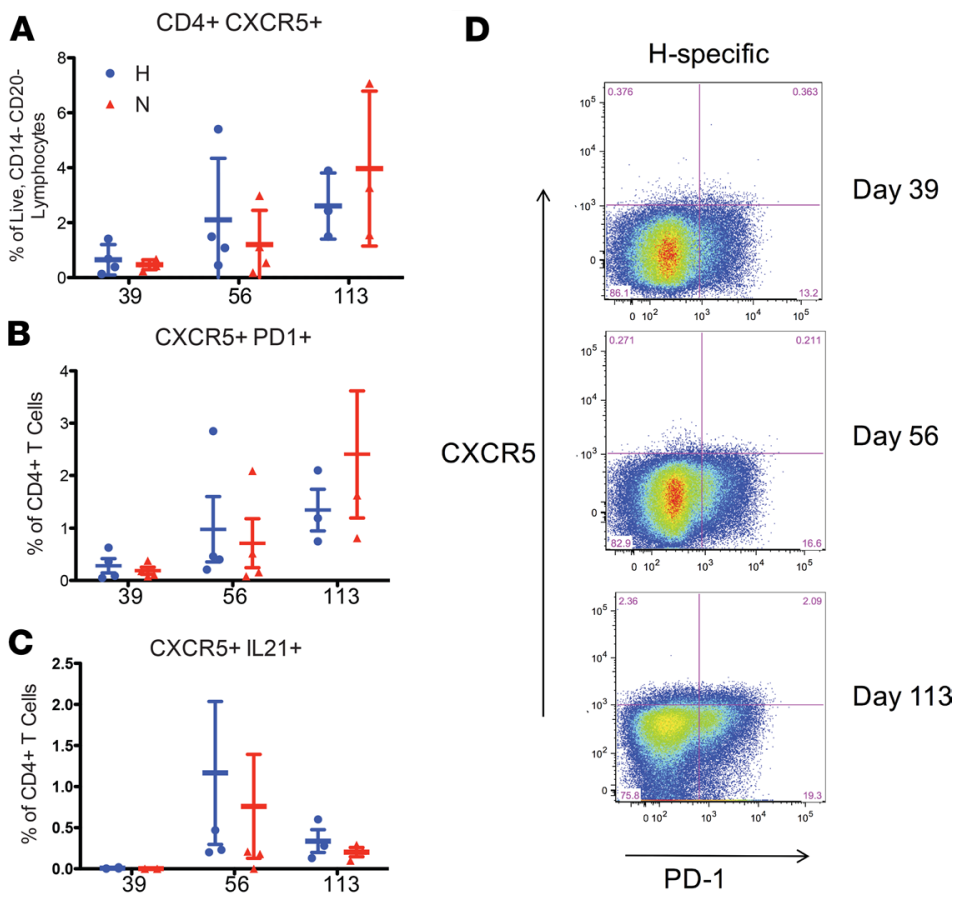

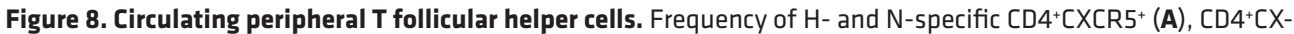
CR5 ${ }^{+}$PD- $1^{+}(B)$, and CD4+CXCR5 ${ }^{+} I L-21^{+}(C)$ T cells in the blood on days $39(n=4), 56(n=4)$, and $113(n=3)$ after infection. (D) Representative flow cytometry plots showing coexpression of PD-1 and CXCR5 on $\mathrm{H}$-specific CD4 ${ }^{+} \mathrm{T}$ cells.

preferential retention of long-lived plasma cells producing antibody against $\mathrm{H}$ in $\mathrm{BM}$ niches would be advantageous for maintaining protective immunity (85).

In summary, primary WT MeV infection of rhesus macaques resulted in a prolonged induction and maturation of the antibody response that correlated with increasing GC proliferation, production of MeV-specific ASCs and pTfh cells. Thus, the continued presence of MeV RNA in lymphoid tissue is postulated to play a critical role in the maturation of virus-specific immune responses and development of lifelong protective immunity, by providing continued antigenic stimulation of both $\mathrm{CD} 4^{+} \mathrm{T}$ cells and $\mathrm{B}$ cells that drive GC formation and continued maturation and production of ASCs.

\section{Methods}

Animals, infection, and sample collection. A total of thirteen 2- to 3-year-old male rhesus macaques (Macaca mulatta) were obtained from the Johns Hopkins Primate Breeding Facility in 3 groups. The Bilthoven strain of WT MeV (genotype C2; gift of Albert Osterhaus, Erasmus University, Rotterdam, The Netherlands) was grown in phytohemagglutinin-stimulated human cord blood cells and assayed by plaque formation on Vero/hSLAM cells (gift from Yusuki Yanagi, Kyushu University, Fukuoka, Japan) (86). Following baseline measurements, monkeys were infected intratracheally with $1 \times 10^{4}$ plaque-forming units of $\mathrm{MeV}$ in $1 \mathrm{~mL}$ PBS. At the onset of the rash, monkeys in the Y group received either vitamin A $(100,000$ units, Vitamin Angels; 14Y, 50Y) or placebo (17Y, 31Y, 46Y) for 2 days. No differences were observed between supplemented and nonsupplemented macaques (11). Y monkeys were analyzed for viremia, RNA persistence, plasma antibody, ASCs in PBMCs and BM, lymph node histology, and pTfh cells. A second group of $\mathrm{X}$ monkeys (31X, 42X, 46X) had previously received a nonimmunogenic experimental sublingual $\mathrm{MeV}$ vaccine and were seronegative for $\mathrm{MeV}$ at the time of study. $\mathrm{X}$ monkeys were analyzed for viremia, RNA persistence, and ASCs in lymph nodes and PBMCs. A third group of $5 \mathrm{U} / \mathrm{V}$ monkeys (15U, 46U, 67U, 40V, $55 \mathrm{~V})$ received no additional manipulation. U/V monkey data for viremia and RNA persistence in PBMCs were previously reported (8) and, in this study, were analyzed for persistence in T cells. Due to sample availability, all assays could not be performed on all animals at all time points. Some data from the Y and U/V experimental groups have been previously reported $(8,11,87)$. 
Heparinized blood was collected from the femoral vein before infection and every 3-14 days after infection for 6 months. PBMCs and plasma were isolated by whole blood gradient centrifugation on Lympholyte-Mammal (Cedarlane Labs). Inguinal lymph node biopsies were performed 38 and 79 days (31X, $42 \mathrm{X}, 45 \mathrm{X})$ or $71 / 72$ days (14Y, 17Y, 31Y, 50Y) and 154/155 days after infection (14Y, 17Y, 31Y). BM was collected by aspiration from the humerus or femur into a heparinized syringe. For all procedures, monkeys were anesthetized with $10-15 \mathrm{mg} / \mathrm{kg}$ ketamine intramuscularly.

Quantification of MeV N gene RNA. MeV RNA in PBMCs and lymph node cells was quantified by qRTPCR as previously described $(8,88)$ or by ddRT-PCR. To analyze individual types of cells, mononuclear cells isolated from PBMCs or LNs were sorted using magnetic beads (Miltenyi Biotec) into CD3 ${ }^{+}, \mathrm{CD}^{2} 0^{+}$, and $\mathrm{CD} 14^{+}$populations. Briefly, for qRT-PCR total, RNA was isolated from $2 \times 10^{6}$ cells and the N gene amplified (Applied Biosystems Prism 7700) using a one-step RT-PCR kit with TaqMan primers (MVN fwd: 5'-GGGTACCATCCTAGCCCAAATT-3'; MVN rev: 5'-CGAATCAGCTGCCGTGTCT-3') and probe (5'-CTCGCAAAGGCGGTTACGGCC). Controls included GAPDH amplification (Applied Biosystems) and RNA isolated from cultured PBMCs from MeV-naive monkeys. Copy number was determined by construction of a standard curve from $1 \times 10^{1}$ to $1 \times 10^{8}$ copies of RNA synthesized by in vitro transcription from a plasmid encoding the Edmonston MeV N gene (MV41 5'-CATTACATCAGGATCCGG-3'; MV42 5'-GTATTGGTCCGCCTCATC-3'). The sensitivity of the assay was 50-100 copies. Data were normalized to the GAPDH control and expressed as [(copies of MeV N RNA)/(copies of GAPDH RNA)] $\times 5000$.

For ddRT-PCR, the RNeasy Plus Micro Kit (Qiagen) was used to isolate RNA. RNA was eluted in RNase free water and $100 \mathrm{ng}$ used to make cDNA using the iScript Advanced cDNA synthesis kit (Bio-Rad). A $20 \mu \mathrm{L}$ mixture of primers, probes, Bio-Rad $2 \times$ Supermix (no dUTP), and $5 \mu \mathrm{L}$ of cDNA was prepared and emulsified with droplet generator oil using a QX-100 droplet generator (Bio-Rad) according to the manufacturer's instructions. Samples were multiplexed with primers and probes specific for MeV N gene (5' FAM) and GAPDH (5' HEX). The droplets were then transferred to a 96-well reaction plate (Eppendorf) and heat-sealed with pierceable sealing foil sheets (Thermo Fisher Scientific). PCR amplification was performed in the sealed plate using a GeneAmp 9700 thermocycler (Applied Biosystems) with the following cycling parameters: 10 minutes at $95^{\circ} \mathrm{C}, 40$ cycles of a 30 -second denaturation at $94^{\circ} \mathrm{C}$, and a 60 -second extension at $59^{\circ} \mathrm{C}$, followed by 10 minutes at $98^{\circ} \mathrm{C}$ and a hold at $12^{\circ} \mathrm{C}$. Immediately following PCR amplification, droplets were analyzed using a QX100 droplet reader (Bio-Rad). All samples and controls were run in quadruplet. Data are reported as [(copies of MeV N RNA)/(copies of GAPDH RNA)] $\times 5000$.

Antibody assays. The plaque reduction neutralization test was used to measure neutralizing antibody against $\mathrm{MeV}$. The Edmonston strain of $\mathrm{MeV}$ was mixed with serially diluted plasma (1:3 to 1:30,000) and assayed for plaque formation on Vero cells (ATCC). Data are reported as the reciprocal of the serum dilution at which the number of plaques is reduced by $50 \%$.

ELISAs were used to measure MeV-specific IgM and IgG in plasma. Maxisorp 96-well plates (Nalgene Nunc International) coated with lysate from MeV-infected Vero cells (1.16 $\mu \mathrm{g} /$ well; Advanced Biotechnologies) were blocked with $2 \%$ nonfat dry milk for 2 hours at $37^{\circ} \mathrm{C}$. Serially diluted plasma $(1: 50$ to $1: 25,600)$ was added and incubated at room temperature for 2 hours. The secondary antibody was HRP-conjugated-goat anti-monkey IgM or IgG (MilliporeSigma). Plates were developed using 3,3',5,5'-tetramethylbenzidine as the substrate and the reaction was stopped using $2 \mathrm{M} \mathrm{H}_{2} \mathrm{SO}_{4}$. Plates were read at $450 \mathrm{~nm}$. The ELISA titer was the highest dilution at which responses were twice the background.

$\mathrm{MeV}$ protein-specific IgG responses were measured using 96-well immunoplates coated with lysates of L cells expressing MeV-H or MeV-F (1:1000) or with baculovirus-generated MeV-N (1:2000) (89, 90). Blocking, serum dilution, IgG detection, and development were performed as above.

To assess the avidity of MeV-specific antibody, ELISAs were performed as described above, and following plasma incubation, increasing concentrations $(0.5$ to $3 \mathrm{M})$ of ammonium thiocyanate $\left(\mathrm{NH}_{4} \mathrm{SCN}\right)$ were added for 15 minutes to disrupt the antigen-antibody interaction. The avidity index was calculated as the concentration of $\mathrm{NH}_{4} \mathrm{SCN}$ required to remove $75 \%$ of bound antibody $\left(\mathrm{AI}_{75}\right)$.

ASCs. Lymph node cells or cells isolated from heparinized blood or BM by density gradient centrifugation with Lympholyte Mammal (Cedarlane Laboratories) were assessed for antibody secretion. Multiscreen HTS HA Opaque plates (Millipore) were coated with MeV-infected Vero cell lysate, H-expressing L cell lysate, baculovirus-expressed $\mathrm{N}$ or with purified goat-anti monkey IgG, IgM, IgA (H\&L) (MilliporeSigma) and incubated at $4^{\circ} \mathrm{C}$ overnight. After incubation, plates were washed twice with PBS and blocked with RPMI plus $10 \% \mathrm{FBS}$ at $37^{\circ} \mathrm{C}$ for 1 hour. Cells were added to plates and incubated for 6 hours at $37^{\circ} \mathrm{C}, 5 \%$ 
$\mathrm{CO}_{2}$. Samples from lymph nodes and blood were serially diluted and run in 6 wells. Samples from BM were run in 8 replicates without serial dilution. After incubation, plates were washed with PBS-T $(1 \times$ PBS + $0.05 \%$ Tween 20) and bound immunoglobulin was detected with HRP-conjugated goat-anti monkey IgG (Nordic; 1:5000). Plates were developed with stable DAB solution (Invitrogen) and read on an immunospot plate reader (Cellular Technology). Data were analyzed using Immunospot version 3.0 software. Data are presented as ASCs per $1 \times 10^{6}$ cells.

Histology and immunohistochemistry. Inguinal lymph nodes were embedded in paraffin and sectioned. Deparaffinized sections were stained with H\&E to assess GCs, Ki-67 (1:100; MM1, Novacastra) to identify proliferating cells, and Masson's trichrome to visualize collagenous connective tissue fibers. To characterize immune cell distribution, sections were stained with anti-CD3 (1:400; A052, Dako) or anti-CD20 (1:1000; L26, Dako). Staining was performed using an automated Leica Bond Max system (Leica Biosystems).

Flow cytometry. Multicolor flow cytometry with intracellular cytokine staining was used to identify $\mathrm{MeV}$-specific peripheral Tfh cells $\left(\mathrm{CD} 4^{+} \mathrm{CXCR} 5^{+} \mathrm{PD}-1^{+}\right)$. Fresh PBMCs $\left(1 \times 10^{6}\right.$ cells per well) were stimulated for 12 hours with pooled overlapping $\mathrm{H}$ or $\mathrm{N}$ peptides $(1 \mu \mathrm{g} / \mathrm{mL})$, peptide diluent DMSO (negative control), or staphylococcal enterotoxin B (positive control). Purified mouse anti-human CD28 (BD Biosciences, CD28.2) and-CD49d (BD Biosciences, 9F10) were included with the peptides or DMSO. All stimulation mixes included protein transport inhibitors GolgiStop and GolgiPlug (BD Biosciences). Live/Dead Fixable Violet Dead Cell Stain Kit (Invitrogen) was used to exclude dead cells from analysis. Before surface staining, cells were incubated with a human FcR block (eBioscience) for 10 minutes on ice. Cells were stained with fluorescently labeled antibodies to the following surface antigens: CD4 FITC (OKT4, BioLegend), CD3 APC-Cy7 (SP34-2, BD Biosciences), CXCR5 PE-Cy7 (MU5UBEE, Invitrogen), and PD-1 PE (EH12.2H7, BioLegend). A "dump channel" was used to exclude CD14+ (PacBlue, M5E2, BD Biosciences) and CD20+ (PacBlue, 2H7, eBioscience) cells. Intracellular staining to detect the transcription factor Bcl-6 (PerCP-Cy5.5, Q21-559, BD Biosciences) and cytokine IL-21 (APC, 3A3-N2, eBioscience) was done following fixation and permeabilization of cells using the Foxp3 Staining Buffer Set (eBioscience). For pTfh phenotyping, the following gating strategy was applied: lymphocytes were gated on singlets and live cells were selected to gate on $\mathrm{CD}^{+}$cells, followed by gating on $\mathrm{CD}^{+} \mathrm{CXCR}^{+}$cells, which were further phenotyped by gating on PD-1, Bcl-6, and IL-21. Samples were run on a BD FACSCanto II flow cytometer and analyzed using BD FACSDiva and FlowJo software.

Statistics. All statistical analysis was performed with GraphPad Prism version 8.0.1. A 2-way mixed-effects ANOVA was used for all statistical analyses, and post hoc analyses included a Tukey's multiple comparisons test. $P$ values less than 0.05 were considered statistically significant. Data are presented as the mean values \pm SD.

Study approval. All studies were performed in accordance with experimental protocols approved by the Johns Hopkins University Animal Care and Use Committee (Johns Hopkins University, Baltimore, MD).

\section{Author contributions}

ANN, WHWL, and DEG planned the studies. ANN, NEP, WHWL, RS, RJA, VKB, DH, and LM performed the studies. ANN and DEG wrote the manuscript with input from all authors.

\section{Acknowledgments}

These studies were supported by research grants R21 AI095981 (to DEG), R01 AI131228 (to DEG), T32 AI007417 (to ANN and RS), and T32 OD011089 (to VKB) from the NIH and by scholarships from the Wisconsin chapter of the Metals Service Center Institute (to NEP) and the Marjorie Gilbert Student Scholarship Fund (to WHWL). We are grateful for the assistance of Jane Yeh for lymph node biopsy acquisition.

Address correspondence to: Diane E. Griffin, Johns Hopkins Bloomberg School of Public Health, 615 N. Wolfe Street, Room E5636, Baltimore, Maryland, 21205, USA. Phone: 410.955.3459; Email: dgriffi6@jhu.edu.

ANN's present address is: Human Vaccine Institute, Duke University School of Medicine, Durham, North Carolina, USA.

WHWL's present address is: Department of Pathology, Columbia University School of Medicine, New York City, New York, USA. 
RS's present address is: Department of Epidemiology, Columbia Mailman School of Public Health, New York City, New York, USA.

NP's present address is: Clinical Microbiology Laboratory, Department of Laboratory Medicine, National Institutes of Health, Bethesda, Maryland, USA.

VKB's present address is: Department of Pathology and Laboratory Medicine, University of North Carolina at Chapel Hill, Chapel Hill, North Carolina, USA.

1. Paules CI, Marston HD, Fauci AS. Measles in 2019 — going backward. N Engl J Med. 2019;380(23):2185-2187.

2. Dabbagh A, et al. Progress toward regional measles elimination - Worldwide, 2000-2017. MMWR Morb Mortal Wkly Rep. 2018;67(47):1323-1329.

3. Auwaerter PG, et al. Measles virus infection in rhesus macaques: altered immune responses and comparison of the virulence of six different virus strains. J Infect Dis. 1999;180(4):950-958.

4. Moss WJ. Measles. Lancet. 2017;390(10111):2490-2502.

5. Moench TR, Griffin DE, Obriecht CR, Vaisberg AJ, Johnson RT. Acute measles in patients with and without neurological involvement: distribution of measles virus antigen and RNA. J Infect Dis. 1988;158(2):433-442.

6. Allen IV, McQuaid S, Penalva R, Ludlow M, Duprex WP, Rima BK. Macrophages and dendritic cells are the predominant cells infected in measles in humans. mSphere. 2018;3(3):e00570-17.

7. Lessler J, Reich NG, Brookmeyer R, Perl TM, Nelson KE, Cummings DA. Incubation periods of acute respiratory viral infections: a systematic review. Lancet Infect Dis. 2009;9(5):291-300.

8. Lin WH, Kouyos RD, Adams RJ, Grenfell BT, Griffin DE. Prolonged persistence of measles virus RNA is characteristic of primary infection dynamics. Proc Natl Acad Sci U S A. 2012;109(37):14989-14994.

9. Permar SR, et al. Prolonged measles virus shedding in human immunodeficiency virus-infected children, detected by reverse transcriptase-polymerase chain reaction. J Infect Dis. 2001;183(4):532-538.

10. Riddell MA, Moss WJ, Hauer D, Monze M, Griffin DE. Slow clearance of measles virus RNA after acute infection. J Clin Virol. 2007;39(4):312-317.

11. Nelson AN, Putnam N, Hauer D, Baxter VK, Adams RJ, Griffin DE. Evolution of T cell responses during measles virus infection and RNA clearance. Sci Rep. 2017;7(1):11474.

12. Panum P. Observations made during the epidemic of measles on the Faroe Islands in the year 1846. Med Classics. 1938;3:829-886

13. Permar SR, et al. Limited contribution of humoral immunity to the clearance of measles viremia in rhesus monkeys. $J$ Infect Dis 2004;190(5):998-1005.

14. Permar SR, et al. Role of CD8(+) lymphocytes in control and clearance of measles virus infection of rhesus monkeys. $J$ Virol. 2003;77(7):4396-4400.

15. Griffin DE. Measles vaccine. Viral Immunol. 2018;31(2):86-95.

16. de Vries RD, Yüksel S, Osterhaus AD, de Swart RL. Specific CD8(+) T-lymphocytes control dissemination of measles virus Eur J Immunol. 2010;40(2):388-395.

17. Helfand RF, Heath JL, Anderson LJ, Maes EF, Guris D, Bellini WJ. Diagnosis of measles with an IgM capture EIA: the optimal timing of specimen collection after rash onset. J Infect Dis. 1997;175(1):195-199.

18. Helfand RF, Kebede S, Mercader S, Gary HE, Beyene H, Bellini WJ. The effect of timing of sample collection on the detection of measles-specific IgM in serum and oral fluid samples after primary measles vaccination. Epidemiol Infect. 1999;123(3):451-455.

19. Nair N, et al. HIV-1 infection in Zambian children impairs the development and avidity maturation of measles virus-specific immunoglobulin G after vaccination and infection. J Infect Dis. 2009;200(7):1031-1038.

20. Amanna IJ, Carlson NE, Slifka MK. Duration of humoral immunity to common viral and vaccine antigens. $N$ Engl J Med. 2007;357(19):1903-1915.

21. Naniche D. Human immunology of measles virus infection. Curr Top Microbiol Immunol. 2009;330:151-171.

22. Chen RT, et al. Measles antibody: reevaluation of protective titers. J Infect Dis. 1990;162(5):1036-1042.

23. de Swart RL, Yüksel S, Osterhaus AD. Relative contributions of measles virus hemagglutinin- and fusion protein-specific serum antibodies to virus neutralization. J Virol. 2005;79(17):11547-11551.

24. Bouche FB, Ertl OT, Muller CP. Neutralizing B cell response in measles. Viral Immunol. 2002;15(3):451-471.

25. Chen CJ, et al. Waning population immunity to measles in Taiwan. Vaccine. 2012;30(47):6721-6727.

26. Christenson B, Böttiger M. Measles antibody: comparison of long-term vaccination titres, early vaccination titres and naturally acquired immunity to and booster effects on the measles virus. Vaccine. 1994;12(2):129-133.

27. Hahné SJ, et al. Measles outbreak among previously immunized healthcare workers, the Netherlands, 2014. J Infect Dis. 2016;214(12):1980-1986.

28. Rosen JB, et al. Outbreak of measles among persons with prior evidence of immunity, New York City, 2011. Clin Infect Dis. 2014;58(9):1205-1210.

29. Loevinsohn G, Rosman L, Moss WJ. Measles seroprevalence and vaccine responses in human immunodeficiency virus-infected adolescents and adults: a systematic review. Clin Infect Dis. 2019;69(5):836-844.

30. Polack FP, Hoffman SJ, Crujeiras G, Griffin DE. A role for nonprotective complement-fixing antibodies with low avidity for measles virus in atypical measles. Nat Med. 2003;9(9):1209-1213.

31. Slifka MK, Matloubian M, Ahmed R. Bone marrow is a major site of long-term antibody production after acute viral infection. J Virol. 1995;69(3):1895-1902.

32. Benner R, Hijmans W, Haaijman JJ. The bone marrow: the major source of serum immunoglobulins, but still a neglected site of 
antibody formation. Clin Exp Immunol. 1981;46(1):1-8.

33. Polack FP, et al. Successful DNA immunization against measles: neutralizing antibody against either the hemagglutinin or fusion glycoprotein protects rhesus macaques without evidence of atypical measles. Nat Med. 2000;6(7):776-781.

34. Vinuesa CG, Linterman MA, Yu D, MacLennan IC. Follicular helper T cells. Annu Rev Immunol. 2016;34:335-368

35. Crotty S. Follicular helper CD4 T cells (TFH). Annu Rev Immunol. 2011;29:621-663.

36. Crotty S. T follicular helper cell differentiation, function, and roles in disease. Immunity. 2014;41(4):529-542.

37. Onabajo OO, George J, Lewis MG, Mattapallil JJ. Rhesus macaque lymph node PD-1(hi)CD4+ T cells express high levels of CXCR5 and IL-21 and display a CCR7(lo)ICOS ${ }^{+} \mathrm{Bcl6}^{+}$T-follicular helper (Tfh) cell phenotype. PLoS One. 2013;8(3):e59758.

38. Schmitt N, Bentebibel SE, Ueno H. Phenotype and functions of memory Tfh cells in human blood. Trends Immunol. 2014;35(9):436-442

39. Morita R, et al. Human blood CXCR5(+)CD4(+) T cells are counterparts of $\mathrm{T}$ follicular cells and contain specific subsets that differentially support antibody secretion. Immunity. 2011;34(1):108-121.

40. Locci M, et al. Human circulating PD $-1^{+} \mathrm{CXCR} 3^{-} \mathrm{CXCR} 5^{+}$memory Tfh cells are highly functional and correlate with broadly neutralizing HIV antibody responses. Immunity. 2013;39(4):758-769.

41. de Swart RL, et al. Predominant infection of CD150+ lymphocytes and dendritic cells during measles virus infection of macaques. PLoS Pathog. 2007;3(11):e178.

42. de Vries RD, et al. Measles immune suppression: lessons from the macaque model. PLoS Pathog. 2012;8(8):e1002885.

43. Laksono BM, et al. Studies into the mechanism of measles-associated immune suppression during a measles outbreak in the Netherlands. Nat Commun. 2018;9(1):4944.

44. Levine B, Hardwick JM, Griffin DE. Persistence of alphaviruses in vertebrate hosts. Trends Microbiol. 1994;2(1):25-28.

45. Murray K, et al. Persistent infection with West Nile virus years after initial infection. J Infect Dis. 2010;201(1):2-4

46. Caviness K, Kuhn JH, Palacios G. Ebola virus persistence as a new focus in clinical research. Curr Opin Virol. 2017;23:43-48.

47. Paz-Bailey G, et al. Persistence of Zika virus in body fluids — final report. N Engl J Med. 2018;379(13):1234-1243.

48. Hirsch AJ, et al. Zika virus infection of rhesus macaques leads to viral persistence in multiple tissues. PLoS Pathog. 2017;13(3):e1006219.

49. Pradhan S, Gupta RK, Singh MB, Mathur A. Biphasic illness pattern due to early relapse in Japanese-B virus encephalitis. J Neurol Sci. 2001;183(1):13-18.

50. Gritsun TS, et al. Characterization of a siberian virus isolated from a patient with progressive chronic tick-borne encephalitis J Virol. 2003;77(1):25-36

51. Noran HH, Baker AB. Sequels of equine encephalomyelitis. Arch Neurol Psych. 1943;49:398-413.

52. Griffin DE, Lin WH, Pan CH. Measles virus, immune control, and persistence. FEMS Microbiol Rev. 2012;36(3):649-662.

53. Shaman J, et al. Asymptomatic summertime shedding of respiratory viruses. J Infect Dis. 2018;217(7):1074-1077.

54. Subissi L, et al. Ebola virus transmission caused by persistently infected survivors of the 2014-2016 outbreak in West Africa. J Infect Dis. 2018;218(supp1_5):S287-S291.

55. Tiffany A, et al. Ebola virus disease complications as experienced by survivors in Sierra Leone. Clin Infect Dis. 2016;62(11):1360-1366.

56. Russell K, et al. Male-to-female sexual transmission of Zika virus-United States, January-April 2016. Clin Infect Dis. 2017;64(2):211-213

57. Ryon JJ, Moss WJ, Monze M, Griffin DE. Functional and phenotypic changes in circulating lymphocytes from hospitalized zambian children with measles. Clin Diagn Lab Immunol. 2002;9(5):994-1003.

58. Griffin DE, Ward BJ, Jauregui E, Johnson RT, Vaisberg A. Immune activation in measles. N Engl J Med. 1989;320(25):1667-1672.

59. Mesin L, Ersching J, Victora GD. Germinal center B cell dynamics. Immunity. 2016;45(3):471-482.

60. Bachmann MF, Odermatt B, Hengartner H, Zinkernagel RM. Induction of long-lived germinal centers associated with persisting antigen after viral infection. J Exp Med. 1996;183(5):2259-2269.

61. Caponetti G, Pantanowitz L. HIV-associated lymphadenopathy. Ear Nose Throat J. 2008;87(7):374-375

62. Simon MA, Chalifoux LV, Ringler DJ. Pathologic features of SIV-induced disease and the association of macrophage infection with disease evolution. AIDS Res Hum Retroviruses. 1992;8(3):327-337.

63. Wong SW, et al. Induction of B cell hyperplasia in simian immunodeficiency virus-infected rhesus macaques with the simian homologue of Kaposi's sarcoma-associated herpesvirus. J Exp Med. 1999;190(6):827-840.

64. Mansfield KG, Westmoreland SV, DeBakker CD, Czajak S, Lackner AA, Desrosiers RC. Experimental infection of rhesus and pig-tailed macaques with macaque rhadinoviruses. $J$ Virol. 1999;73(12):10320-10328.

65. Luppi M, et al. Human herpesvirus- 8 DNA sequences in human immunodeficiency virus-negative angioimmunoblastic lymphadenopathy and benign lymphadenopathy with giant germinal center hyperplasia and increased vascularity. Blood. 1996;87(9):3903-3909.

66. Zeng M, et al. Cumulative mechanisms of lymphoid tissue fibrosis and T cell depletion in HIV-1 and SIV infections. J Clin Invest. 2011;121(3):998-1008.

67. Polack FP, et al. Production of atypical measles in rhesus macaques: evidence for disease mediated by immune complex formation and eosinophils in the presence of fusion-inhibiting antibody. Nat Med. 1999;5(6):629-634.

68. Tas JM, et al. Visualizing antibody affinity maturation in germinal centers. Science. 2016;351(6277):1048-1054

69. Klein F, et al. Somatic mutations of the immunoglobulin framework are generally required for broad and potent HIV-1 neutralization. Cell. 2013;153(1):126-138.

70. Lindquist RL, Niesner RA, Hauser AE. In the right place, at the right time: spatiotemporal conditions determining plasma cell survival and function. Front Immunol. 2019;10:788.

71. Reinhardt RL, Liang HE, Locksley RM. Cytokine-secreting follicular T cells shape the antibody repertoire. Nat Immunol. 2009;10(4):385-393.

72. de Vinuesa CG, et al. Germinal centers without T cells. J Exp Med. 2000;191(3):485-494

73. Breitfeld D, et al. Follicular B helper T cells express CXC chemokine receptor 5, localize to B cell follicles, and support immunoglobulin production. J Exp Med. 2000;192(11):1545-1552. 
74. Perreau M, et al. Follicular helper T cells serve as the major CD4 T cell compartment for HIV-1 infection, replication, and production. J Exp Med. 2013;210(1):143-156.

75. Blink EJ, Light A, Kallies A, Nutt SL, Hodgkin PD, Tarlinton DM. Early appearance of germinal center-derived memory B cells and plasma cells in blood after primary immunization. J Exp Med. 2005;201(4):545-554.

76. Garimalla S, et al. Differential transcriptome and development of human peripheral plasma cell subsets. JCI Insight. 2019;4(9):126732.

77. Halliley JL, et al. Peak frequencies of circulating human influenza-specific antibody secreting cells correlate with serum antibody response after immunization. Vaccine. 2010;28(20):3582-3587.

78. Lee FE, et al. Circulating human antibody-secreting cells during vaccinations and respiratory viral infections are characterized by high specificity and lack of bystander effect. J Immunol. 2011;186(9):5514-5521.

79. Lee FE, Falsey AR, Halliley JL, Sanz I, Walsh EE. Circulating antibody-secreting cells during acute respiratory syncytial virus infection in adults. J Infect Dis. 2010;202(11):1659-1666.

80. Bernasconi NL, Traggiai E, Lanzavecchia A. Maintenance of serological memory by polyclonal activation of human memory B cells. Science. 2002;298(5601):2199-2202.

81. Odendahl M, et al. Generation of migratory antigen-specific plasma blasts and mobilization of resident plasma cells in a secondary immune response. Blood. 2005;105(4):1614-1621.

82. Radbruch A, et al. Competence and competition: the challenge of becoming a long-lived plasma cell. Nat Rev Immunol. 2006;6(10):741-750.

83. Mina MJ, et al. Measles virus infection diminishes preexisting antibodies that offer protection from other pathogens. Science. 2019;366(6465):599-606.

84. Oracki SA, Walker JA, Hibbs ML, Corcoran LM, Tarlinton DM. Plasma cell development and survival. Immunol Rev. 2010;237(1):140-159.

85. Slifka MK, Antia R, Whitmire JK, Ahmed R. Humoral immunity due to long-lived plasma cells. Immunity. 1998;8(3):363-372.

86. Ono N, Tatsuo H, Hidaka Y, Aoki T, Minagawa H, Yanagi Y. Measles viruses on throat swabs from measles patients use signaling lymphocytic activation molecule (CDw150) but not CD46 as a cellular receptor. J Virol. 2001;75(9):4399-4401.

87. Lin WH, et al. Successful respiratory immunization with dry powder live-attenuated measles virus vaccine in rhesus macaques. Proc Natl Acad Sci U S A. 2011;108(7):2987-2992.

88. Pan $\mathrm{CH}$, et al. Modulation of disease, $\mathrm{T}$ cell responses, and measles virus clearance in monkeys vaccinated with $\mathrm{H}$-encoding alphavirus replicon particles. Proc Natl Acad Sci U S A. 2005;102(33):11581-11588.

89. Hummel KB, Erdman DD, Heath J, Bellini WJ. Baculovirus expression of the nucleoprotein gene of measles virus and utility of the recombinant protein in diagnostic enzyme immunoassays. J Clin Microbiol. 1992;30(11):2874-2880.

90. Beauverger P, Buckland R, Wild F. Establishment and characterisation of murine cells constitutively expressing the fusion, nucleoprotein and matrix proteins of measles virus. J Virol Methods. 1993;44(2-3):199-210. 